Wanke, M., Grözinger, K.-H. \& Hartmann, R. (1966). Langenbecks Arch. klin. Chir. 3I 4, 99.

Watson, R. F. \& Rothbard, S. (1954). F. exp. Med. 99, 535.

WANKE, M., OTt, G. (I969). Erfahrungen zum temporären Hautersatz mit DreischichtKollagenfolien- (in print).

Wanke, M., Grözinger, K.-H., Hartmann, R. (I966). Langenbecks Arch. klin. Chir. 3II, I, pp. 99-I I6 (in English).

WANKE, M. (I966). Mschr. Unfallheilk. 69, $50 \mathrm{I}$.

Wanke, M., Collins, R. L. L., Hartmann, R., Linder, M. M. \& Sebening, H. (I967). Frankf. Z. Path. 77, I25.

WANKE, M. \& GRÖZINGER, K.-H. (1965). Klin. Wschr. 43. 975.

WANKE, M. \& GRÖZINGER, K.-H. (I967). Wehrmed. Mschr. II, I 54.

\title{
BED SORES TREATED WITH NEGATIVE AIR-IONS
}

\author{
By Dr. G. URsu \\ Institute of Physiotherapy and Motor Re-Education, Selvapiana del Circeo, Italy
}

I USED negative ionised air in the treatment of four paraplegic patients with pressure sores. I have applied this treatment in Italy under the guidance of Dr. G. Pedacchie, Director of the Institute of Physiotherapy and Motor Re-Education, Selvapiana del Circeo.

\section{INTRODUCTION}

The ionisation of air (positive or negative) can occur naturally as in cosmic radiations, ionising radiations and so on and artificially using the apparatus called the air-ions generator.

In terrestrial conditions the oxygen is that gas which can be ionised. The physical phenomenon is produced in the following way: the oxygen atom is composed of eight protons-the positive charges of atom which constitute the atomic nucleus - and eight electrons situated on the two orbits, which represent the negative charge of the atom. The electrical neutrality of the oxygen atom results from the balance of forces between electrons and protons, in other words between the negative and positive charges.

\section{METHOD}

The apparatus that we have constructed and which we are using for oxygen ionisation (from ordinary air) is producing an electronic bombardment and a disturbance of atomic balance, which results in negative and positive oxygen-ions in equal parts. By means of an electrical system the apparatus is producing the 
electrical neutralisation of the positive oxygen-ions, so that only the negative oxygen-ions are left.

Animal experiments showed that the atmospherical ionised oxygen when applied directly over the sores (by thermic agents and so on) has a favourable action in the epithelisation of sores by three main effects: (I) antiseptic effect; (2) the stimulation of granulation tissue; and (3) accelerating the growth of epithelium.

Starting from the facts already known in other papers and from these experimental results, we have applied local treatment by negative oxygen-ions (air-ions) in four cases with pressure sores. The results are the subject of the present information.

\section{MATERIAL}

Patient A, aged 35, traumatic paraplegia incomplete below $\mathrm{T}_{7}$, had multiple sores. $\mathrm{He}$ was injured in 1964 and developed trochanteric pressure sores the following year.

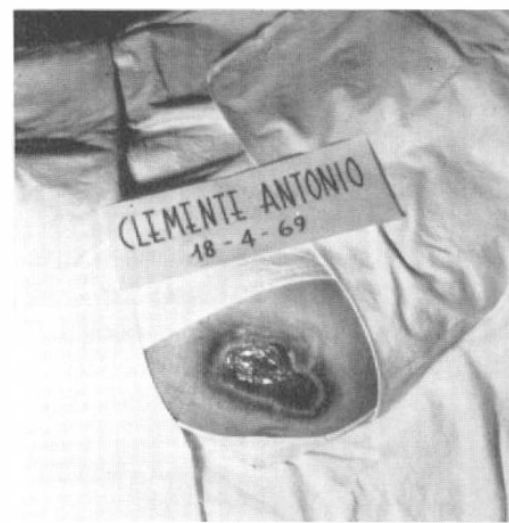

FIG. I

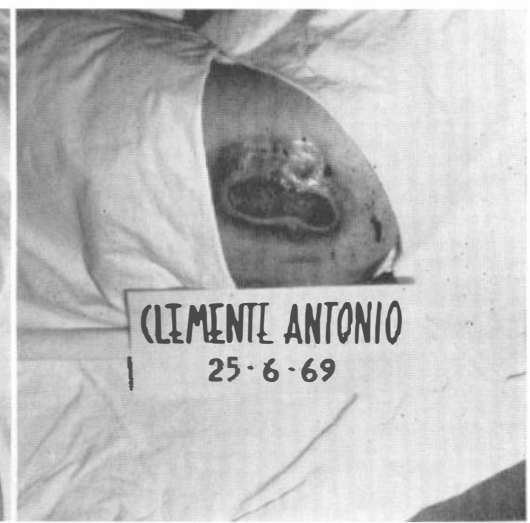

FIG. 2

Was admitted to Selvapiana Institute in 1965 and since then the sores have healed with the exception of the right trochanteric one (fig. I). Treatment with negative oxygen-ions was started on I8 April 1969 every day for 30 to 60 minutes. On 25 June the sore had greatly improved (fig. 2). During this period of treatment the bedsores were dry and clean almost every day.

Patient B, aged 46, traumatic paraplegia complete below TI2, had severe multiple pressure sores. Was admitted to Selvapiana Institute on 3 June I968. Treatment of the right trochanter sore was started on I8 April I969. Again the sore was dry and clean throughout.

Patient C, aged 22, traumatic tetraplegia complete below $\mathrm{C}_{5}$ with severe multiple sores. He was injured in December I968 and was admitted to Selvapiana Institute in January 1969. On I 8 April 1969 we started treatment. On the right calcaneus treatment was given without the new method, on the left calcaneus, where the sore was larger, with the negative oxygen-ions (fig. 3). On 25 June progress was more advanced on the left than on the right (fig. 4).

Patient D, aged 42, tetraplegia incomplete below C6, had severe multiple sores. He was injured in January 1967 and was admitted to Selvapiana Institute on I6 


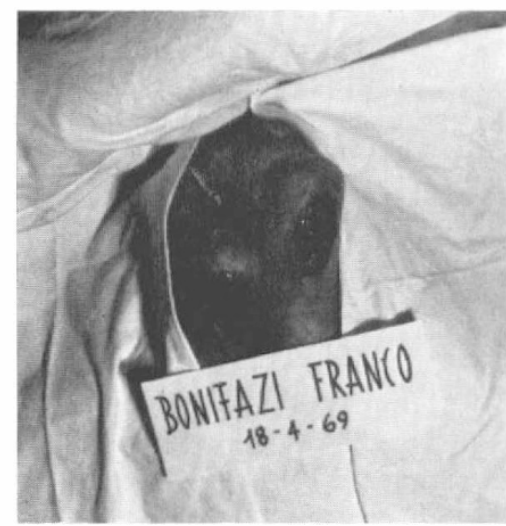

FIG. 3

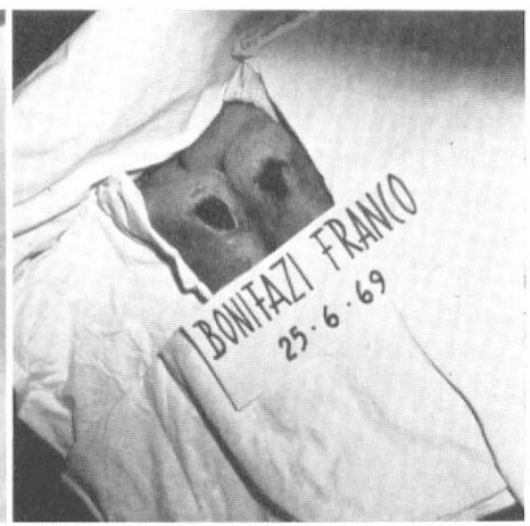

Fig. 4

October 1968. Since then the sores have healed except for the right and left trochanters. On I8 April 1969 he started the treatment with negative oxygen-ions on the right trochanteric sore.

On 25 June, after negative oxygen-ions therapy, the size of the sore was greatly diminished.

During the period of treatment with negative oxygen-ions (air-ions) the patients had no other treatment, locally or generally, except for daily sterile dressings after treatment.

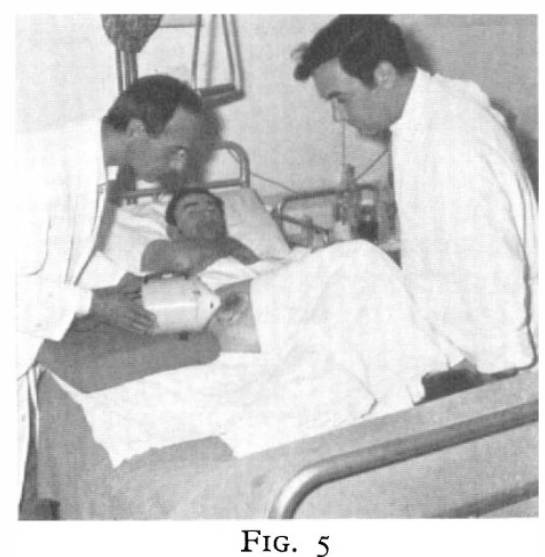

The handling of the apparatus is very simple. It can be handled even by a nurse (fig. 5).

\section{CONCLUSION}

I. Treatment with negative oxygen-ions (air-ions) was applied in four cases (two tetraplegic and two paraplegic) to pressure sores which did not heal with the usual treatment. 
2. The aim of this information is merely to draw attention to the possibilities of treatment with negative oxygen-ions (air-ions). So far we have too few cases observed for too short a period to make definite conclusions.

Acknowledgments. I am greatly indebted to Professor Sir Ludwig Guttmann and Dr. J. J. Walsh for giving me the possibility of participating at this Congress. I would like to thank Dr. Michaelis, Mr. Hyslop, Dr. Frankel and Dr. Vernon for their help in England and I acknowledge the encouragement given by Professor Houssa (Bruxelles) and Dr. Paeslack (Heidelberg).

\section{Discussion}

Chairman. Thank you very much, and now the papers of Dr. Stoop and Dr. Ursu are open for discussion, and perhaps one of the questions that might be relevant is the question of post hoc or propter hoc.

J. Cibeira (Argentine). Our method is that we believe in the principle that with any kind of bed we can avoid ulcers if you know how to treat the spinal cord injuries. But, if you don't know how to treat spinal cord injuries any kind of bed can be bad. Secondly, I feel afraid of slings, I may feel afraid of a special bed in which I cannot move the patient, because the very important thing is to move the patient by active or passive movements. Not only the physiotherapist has to move the patient, nurses, the doctor, everybody has to move the patient, if he cannot move himself. We have to treat the patient as an entity.

Sir Ludwig GutTmanN. Whenever I gave a lecture to physiotherapists or other paramedical people in the past, I was asked in the discussion: "What do you think about the value of ultraviolet light treatment ?' My reply: 'Before I answer your question, please, tell me what are you doing with ultraviolet light ?' The answer was monotonous: 'The doctor and the nurse get fed up with the treatment of the sore, and as a last resort they call in the physiotherapist. What we do is this: we clean the sore, we clean the surrounding area and then apply the ultraviolet light and make proper dressings. Of course, we warn the nurses that no pressure is applied to the sore.' My reply: 'You are marvellous, do exactly the same but leave off the ultraviolet light'. Now, the reason why I am telling you this is that when one introduces a new treatment of pressure sores one has to make controls with the conventional treatment used previously. The basic treatment is the prevention of pressure from the sore and the rate of healing can be determined by a very simple method, always keeping in mind to keep the patient under the same general management: Two decoated X-ray films, one sterile, which is placed over the wound and on top the record film, and size of the sore is drawn on that film every 4 to 5 days. Whatever the treatment may be - whether it is oxygen or nitrogen or lukewarm cheese-one can thus evaluate scientifically the rate of healing. Then, one knows whether one treatment is in any way superior to any other one. You have seen from the dates of the photographs which Dr. Ursu demonstrated that the improvement of these relatively small superficial sores took 2 to $2 \frac{1}{2}$ months which, I suggest, is not extraordinary. I am sorry that Dr. Stoop hasn't shown us any photographs from which one could have concluded whether his technique is in any way superior to any other.

P. Dollfus (France). May I sum up what Dr. Vilan in Paris has said, very rightly: 'You can put anything you like on a pressure sore, except the patient'.

Chairman. Well, gentlemen, perhaps you will agree with me that, as not infrequently, Dr. Dollfus has effectively closed the discussion. 